\title{
SOBRE UM ENTENDIMENTO IRRACIONAL
}

\author{
Márcio Francisco Rodrigues Filho ${ }^{1}$ \\ Universidade do Vale do Rio dos Sinos (UNISINOS) \\ (D) https://orcid.org/0000-0003-0851-7074
}

\section{RESUMO:}

Apresento aqui por que Schopenhauer entende a natureza como um conceito construído pelo homem, abstrata e conceitual: uma palavra. Schopenhauer reformulou o idealismo transcendental de Kant para que os conceitos do entendimento não fizessem referência à sensibilidade, porque animais tem experiência do mundo fenomênico, ao contrário do que a teoria kantiana nos leva a crer. Afinal, em Kant, animais teriam de lidar com conceitos para representar objetos, o que Schopenhauer nega. Na teoria schopenhaueriana nossas percepções não necessitam das categorias do entendimento (conceitos, linguagem) para elaborar o objeto da experiência possível e tornar-se representação. O entendimento kantiano será mostrado como um objeto híbrido: meio representação, meio coisa-em-si, pois Kant misturou o pensar e o intuir, tornado a experiência e o mundo objetivo dependentes do entendimento (conceitual). Porém, para Schopenhauer o objeto individual, as percepções são independentes do pensamento abstrato. $\mathrm{O}$ pensamento se envolve com conceitos e abstrai o que é comum dos objetos, originando-os. Já o entendimento é irracional, intuitivo e perceptivo.

PALAVRAS CHAVE: Schopenhauer; Kant; Intuição; Entendimento; Razão.

\section{OVER A UNDERTANDING IRATIONAL}

\begin{abstract}
:
Present here that Schopenhauer understands nature as a concept built by man, abstract and conceptual: a word. Schopenhauer reformulated transcendental idealism of Kant to the concepts of understanding did not make reference to sensitivity, because animals have experience of the phenomenal world, contrary to what Kant's theory leads us to believe. After all, in Kant, animals would have to deal with concepts to represent objects, which Schopenhauer denies. In Schopenhauer's theory our perceptions do

${ }^{1}$ Doutorando em Filosofia pela Universidade do Vale do Rio dos Sinos (UNISINOS), Rio Grande do Sul - Brasil. Bolsista CAPES/PROSUP. E-mail: marcio.francisco.rodrigues@gmail.com
\end{abstract}


not need the categories of understanding (concepts, language) to draw the object of possible experience and become representation. The Kantian understanding will be shown as a hybrid object: through representation, middle thing-in-itself, as Kant mixed thinking and intuition, making the experience and the dependent objective world of understanding (conceptual). But for Schopenhauer the individual object, perceptions are independent of abstract thought. The thought engages with concepts and abstract what is common objects, causing them. But the understanding is irrational, intuitive and perceptive.

KEYWORDS: Schopenhauer ; Kant ; intuition ; understanding; Reason.

\section{Schopenhauer e Kant: métodos distintos}

Schopenhauer considera que seu método de pesquisa é diferente do kantiano, pois parte do conhecimento imediato, intuitivo, produzido pelo entendimento através do espaço, tempo e causalidade. Essa atividade é uma função do cérebro, portanto, fisiológica. A diferença marcante entre o método de Kant e o de Schopenhauer está no ponto de partida de cada um. Kant parte do conhecimento mediato, refletido, enquanto Schopenhauer parte do imediato, do intuitivo (percepção intuitiva irracional, não conceitual). "Pode-se compará-lo com aquele que mede a altura de uma torre pela sua sombra e eu com quem aplica imediatamente o metro" (SCHOPENHAUER, 1991, p. 115).

Em Schopenhauer a razão terá um papel secundário em relação à intuição, pois "o entendimento é o correlato subjetivo das intuições, a razão, corresponde subjetivamente aos conceitos, ou seja, as representações abstratas" (CACCIOLA, 1989, p. 92). O conteúdo da razão é um conhecimento intuitivo que nos é dado através de representações que nos são trazidas e pensadas através de intuições e conceitos. Porque, para Schopenhauer, a intuição em Kant não tem entendimento e é puramente sensorial. Em Kant um objeto, ou seja, temos experiência de algo que seja aprendido no pensamento. O pensamento é levado para dentro da intuição, ou sensibilidade. $\mathrm{O}$ objeto do pensamento se torna de novo um objeto e acaba por perder seu caráter de universalidade de abstração, pois ao invés de coisas universais recebe coisas particulares. Kant é levado a colocar a intuição para dentro do pensamento, distinguindo o intuir do pensar. Mas, das coisas individuais, Kant faz delas parte do pensar e parte do intuir. Diferente de Schopenhauer, que pensa que "nossa intuição empírica é diretamente objetiva, mesmo porque, parte do nexo causal. Seu objeto são as coisas imediatamente, não representações diferentes delas" (SCHOPENHAUER, 1991, p. 108).

Para Kant, o entendimento é uma faculdade de julgar, não uma faculdade da intuição; não é intuitivo, mas discursivo. Isso tudo porque, 
como já vimos anteriormente, na teoria da experiência proposta por Kant a natureza é um conceito e não um dado intuitivo, isto é, os objetos reais, empíricos, as coisas materiais, físicas somente existem para nós, para o nosso conhecimento, enquanto fenômenos submetidos às formas da nossa sensibilidade, espaço e tempo, e o múltiplo da intuição, esse material dado, necessita ser objetivado, através da síntese desse múltiplo, que é uma função das categorias do entendimento. As categorias, por sua vez, fazem a síntese desse múltiplo da intuição formando o objeto da experiência possível, isto é, o objeto transcendental, o objeto das categorias. O conceito passa a ser um modo de conhecer e não uma ideia abstrata, porque ele se torna através do trabalho efetuado pelas categorias, uma das formas do conhecimento que possibilita que se alcance a experiência.

Um juízo para Schopenhauer é, diferentemente de Kant, uma representação de uma representação, um conhecimento mediato. Essas representações de representações, Schopenhauer as chama de representações abstratas, inerentes ao homem, pois formam uma única classe de representações que são os conceitos. A divergência principal entre Kant e Schopenhauer, portanto, estará em que, para Kant, para se determinar um objeto é necessário que apliquemos os conceitos puros do entendimento às intuições possíveis, e, em Schopenhauer, a intuição empírica é diretamente objetiva. Por essa razão, Shopenhauer entende que, quando pensamos, já abandonamos o individual e nos encontramos no território dos conceitos. Como veremos a seguir, Schopenhauer não admite que os conceitos deem realidade as intuições. O que torna mais claro o problema geral desse trabalho, pois, se é assim que o conhecimento ocorre, então animais irracionais jamais poderiam conhecer o mundo objetivo? Schopenhauer poderá nos dar uma resposta, pois para ele, a intuição como já vimos é empírica, é uma tarefa do entendimento: espaço, tempo e causalidade, que cria esse mundo dos fenômenos. Por isso, as representações abstratas são um tipo de representação que, por lidarem com conceitos, e não mais com intuições, é que difere o homem dos animais e, é isso, que faz com que as representações abstratas sejam chamadas de razão:

A diferença essencial entre o homem e os demais animais - é a razão, faculdade exclusiva do homem - tem seu fundamento em que só o homem é capaz de ter uma classe de representações que o animal irracional não participa. Esta classe é composta de conceitos, ou seja, as ideias abstratas, contrapondo as meras percepções, as quais, toda via, procedem aqueles. A imediata consequência disso, é que o animal não fala nem rir; mas a consequência mediata é um todo muito grande que separa a vida humana da vida animal, pois pela percepção dos conceitos abstratos, a motivação recebe também uma forma especial (SCHOPENHAUER, 1950, p. 78).

Sobre um entendimento irracional - Márcio Francisco Rodrigues Filho 
Para Schopenhauer, o entendimento é o mesmo no animal e no homem. Trata-se de um conhecimento obtido através de causas, uma faculdade de ligar o efeito à causa, apenas isso. Mas em Kant é diferente. $\mathrm{Na}$ estética transcendental, Kant nos apresenta duas "intuições puras" (formas a priori da sensibilidade: tempo e espaço). A causalidade só entra em questão na lógica transcendental (os doze conceitos puros do entendimento: categorias). Dessas categorias, Schopenhauer conservará apenas a relação de causa e efeito e "considera indispensável jogar fora as onze outras categorias, fruto do gosto gótico de Kant pelas complicações inúteis e falsas simetrias" (LEFRANC, 2008, p. 70). Ao restringir a função do intelecto à aplicação da lei da causalidade, Schopenhauer terá de estender essa função, porque é ela que irá assegurar a objetividade do conhecimento sensível tanto no animal como no homem, fato que o fará distinguir o intelectual da razão, ou seja: intelecto é uma coisa, a razão é outra.

Como visto no trecho acima, Schopenhauer nos diz que é exatamente porque os animais não conhecem por conceitos, isto é, porque não têm acesso ao "mundo abstrato", racional, que eles não falam nem riem, já que não têm uma linguagem discursiva, e tampouco humor. Isso fica mais claro se tivermos em mente que Schopenhauer possui uma teoria fisiológica das cores, isto é, as cores pertencem aos olhos. As cores são uma função da retina, que diferencia o fenômeno cromático. São ações fisiológicas que acontecem no sujeito, pois toda a visão é intelectual, até porque, sem o intelecto, não haveria a visão ou a percepção de objetos (ou cores):

\begin{abstract}
mas restaria a mera sensação de que, como dor ou bem-estar, poderia ter quando muito um significado em relação à vontade, mas seria apenas uma alternância de estados vazios de significado, em nada semelhante ao conhecimento, [...] o conhecimento de um objeto ocorre antes de mais nada pelo fato de que o intelecto relaciona toda a impressão que o corpo recebe à sua causa, colocando num espaço visto a priori, de onde advém o efeito, reconhecendo assim a causa como atuante, como real (SCHOPENHAUER, 2003, p. 29).
\end{abstract}

As representações abstratas, função da razão, que nos diferencia dos demais animais, estão sobrepostas às representações intuitivas, tendo o papel de observar essas últimas no seu conjunto. Representam em segundo grau, ou seja, são representações de representações. Têm a função de simplificar a intuição (intuição empírica: matéria do entendimento) e tornála acessível a todos.

Vamos supor que eu seja o inventor da cadeira, que antes de mim, ou seja, antes de eu ter inventado a cadeira, só existiam banquetas. Então dei o nome de cadeira a minha invenção, porque, além dela ter quatro pernas e um acento, assim como a banqueta, ela também tem um encosto, o que a faz diferente da banqueta. Dessa forma, o conceito de cadeira, por ser um dado abstrato e não intuitivo, refere-se às cadeiras em geral, a como elas devem

Sobre um entendimento irracional - Márcio Francisco Rodrigues Filho 
ser: uma peça, ou um móvel, que tem quatro pernas, um acento e um encosto para as costas e não a uma cadeira em específico, individual, que, por exemplo, pode ser aquela, a primeira cadeira inventada por mim, que não deixou de ser de fato conhecida primeiro enquanto objeto, através do entendimento. Essa forma, o animal pode conhecer, através da intuição. Mas, para ele, cada objeto é individual e único, ele não pode conhecer por conceitos.

A razão é uma cópia abstrata da intuição, capaz "até de suscitar a ilusão de que ela mesma seria o modelo verdadeiro" (PERNIN, 1995, p. 63). Graças a sua regularidade, ordem previsível, essas representações nos inclinam a uma falsa confiança. Schopenhauer foca suas forças para tentar abalar a confiança na razão (faculdade das representações abstratas), como fazem à ciência e a filosofia, quando encarregam à racionalidade de garantir a certeza, a verdade e a felicidade. Pois, tal esperança assenta sobre a razão todas as formas do princípio de razão suficiente, "ao passo que ela rege apenas uma de suas formas; praticamente toda conduta" (PERNIN, 1995, p. $63)$.

O que produz conhecimento não é a razão e sim as representações submetidas ao princípio de razão no entendimento, através da lei da causalidade. A razão serve apenas para classificar, fixar e combinar os conhecimentos imediatos do entendimento através de conceitos, tornando-os claros e inteligíveis, o que permite que possamos passar esses conhecimentos adiante, através da linguagem e até mesmo "fazer ciência". Assim, as representações abstratas dominam as representações intuitivas em seu conjunto. É por isso que, para Schopenhauer, o homem atribui à razão a dominação do mundo.

$\mathrm{Na}$ intuição ainda não há duvida, nada está interpretado; nele as representações estão apenas submetidas à pura intuição. No pensamento abstrato, ou seja, com a razão, já há dúvida e erro. Ao se especular sobre algo, e também na prática, teremos a ansiedade e o arrependimento, pois o homem paga o preço dessa suposta dominação do mundo através da mesma faculdade que o permite tornar sensível ao sofrimento dele próprio, dos outros e o revela a morte antecipadamente, levando-o para o futuro para deixá-lo na agonia do presente. A memória, ao trazer as alegrias, traz consigo a nostalgia, a saudade e as dores do passado. Somos o único ser que tem em mente o passado e o futuro, estando preso na angústia do presente, coisa que os outros seres, dotados de inteligência apenas, estão livres. Porém, no homem, diferente de todos os outros seres existentes, há outra faculdade de conhecer por reflexão, o que, para Schopenhauer, não passa de um reflexo da intuição, muito embora a sua essência e constituição difiram totalmente dela. Por isso, os animais vivem no presente, o homem, além disso, no futuro e no passado; [...] o homem pode, graças às noções abstratas, libertar-se do presente nas suas determinações. (SCHOPENHAUER, 1980, p. 53).

Sobre um entendimento irracional - Márcio Francisco Rodrigues Filho 
Para Schopenhauer, a linguagem é o primeiro produto e o instrumento necessário da razão, coisa que os animais não têm. $\mathrm{O}$ entendimento, com sua função própria de conhecer de imediato a noção de causa e efeito, em relação à intuição do mundo real, nada mais que um modo variado dessa função primitiva. O mesmo acontece com a razão, que tem apenas uma função essencial: formar conceitos. As representações abstratas diferenciam-se das representações intuitivas (intuições empíricas), pois retiram dessas o que não se pode perceber isoladamente. São extratos: representações que simplificam, abreviam as representações intuitivas, ficando apenas com o essencial, conservando a parte de que se precisa. Não são ideias, não podem nos dar conhecimento do absoluto; assim, cada grau de sua abstração é igual a uma perda de parte da intuição. A abstração de um conceito é a condição de sua extensão, de possibilidade de generalizá-lo. Tal extensão não é sua definição, mas uma parte secundária: a lógica é a teoria das relações dessas generalizações dos conceitos. Os conceitos correspondem ao princípio de razão suficiente do conhecimento regendo a quarta parte das representações (liga entre si as representações abstratas remetem instantaneamente umas as outras).

Schopenhauer crê que esse jogo de remissão conceitual tenha um termo, pois chegará o momento em que esta série de princípios de conhecimento repousará num conceito fundamentado no conhecimento intuitivo, pois a abstração está assentada na intuição; de onde tira sua inteligibilidade (PERNIN, 1995, p. 65-66). Em outras palavras, não são os nervos que sentem através da sensação, mas sim a percepção, a capacidade de sentir do corpo que sentem através do nervos, pois a sensação, "ao ser atingida pela luz através do olho, pelo som através do ouvido [...], produz sensações especificamente diferentes" (SCHOPENHAUER, 2003, p. 31).

Assim, é através da razão são feitos os conceitos a partir da linguagem que os reúne. Por ter uma origem discursiva, não permite uma intuição racional. A classe particular das representações abstratas é a linguagem, que é um fenômeno da razão. Tais conceitos formados pela linguagem são distintos das representações intuitivas; porém, há uma relação necessária entre elas, o que, segundo Schopenhauer, proporciona a sua essência e a sua realidade. A reflexão, portanto, não é cópia, mas mera imitação "barata", uma reprodução da intuição. Embora seja muito cara para nós, a reflexão é diferente de seu original, isto é, da matéria de que é feita. Por isso, "pode-se dizer com muita exatidão que os conceitos são representações de representações" (SCHOPENHAUER, 1980, p. 58).

Disso Schopenhauer conclui que nos animais é a ausência de razão que os limita às representações intuitivas imediatamente presentes no tempo. Isto é, limita-os aos objetos reais, porque eles não podem refletir sobre suas próprias intuições. Em outras palavras, os animais estão presos aos objetos representados no tempo e no espaço através do entendimento e suas formas, que é uma função do cérebro. Assim, os cérebros dos demais

Sobre um entendimento irracional - Márcio Francisco Rodrigues Filho 
animais não-humanos não podem refletir. Nós humanos, pelo contrário, com a ajuda do conhecimento in abstracto, podemos abarcar não só o presente, que é sempre limitado, mas o passado e o futuro. "O que são os olhos, no espaço, para o conhecimento sensível, é-o a razão, no tempo, para o conhecimento interior. (SCHOPENHAUER, 1980, p. 115-116). Por isso, todo o valor do conhecimento abstrato, para Schopenhauer está na intuição, já que isso põe a consciência "imediata e intuitiva muito acima do conhecimento abstrato, do simples conceito; ele dá ao conhecimento empírico a preeminência sobre o conhecimento lógico" (SCHOPENHAUER, 1980, p. 116).

A criança, diz Schopenhauer, nas suas primeiras semanas de vida, não vê, porque ainda não sabe usar o intelecto, ou seja, as formas a priori presentes na consciência: tempo, espaço e causalidade (é, enfim, um animal ainda em desenvolvimento). Contudo, pouco a pouco, quando começa a apreender a utilizar o intelecto, a criança consegue passar da sensação até a visão e à percepção, conseguindo por fim perceber o mundo objetivo de forma inteligente. A criança, por fazer comparações das impressões que recebe, apalpa e investiga a causa do som, se valendo do paladar e do olfato para conhecer um objeto. No entanto, é somente depois disso que a criança apreende a usar a razão e começa a falar, a entender o que escuta e a pensar. (SCHOPENHAUER, 2003, p. 33). "Quando vemos dois objetos como um só; isso ocorre porque cada um deles é visto com um olho diferente, mas afeta em cada um os pontos [...] da retina correspondentes entre si" (SCHOPENHAUER, 2003, p. 39). Enfim, o intelecto puro é irracional, é o mundo da intuição, isto é, apenas do entendimento, algo irracional, "aconceitual" o mundo a que os animais irracionais estão presos, por não poderem refletir assim como nós, seres humanos, através de conceitos. A razão é abstrata e distintiva do intelecto, sabemos disso, ao passo que o intelecto puro não. Isso explica porque podemos iludir os animais com facilidade: "ilusão mantém-se intacta, pois o intelecto e a sensibilidade, são inacessíveis para os princípios da razão, isto é, são irracionais (SCHOPENHAUER, 2003, p. 41). Daí, a conclusão schopenhaueriana de que não existe visão sem intelecto, pois é exatamente isto, o intelecto que "difere os animais das plantas, como a razão difere os homens dos animais, pois o caráter verdadeiramente marcante da animalidade é o conhecer, e esse exige sem dúvida o intelecto" (SCHOPENHAUER, 2003, p. 43-44).

Pelo exposto até aqui, esperamos ter demonstrado as diferenças gritantes entre a concepção de Schopenhauer sobre a faculdade de julgar (fruto da razão e não do entendimento) e a concepção kantiana de juízo. Para Schopenhauer, é a razão o que nos difere dos demais animais, não o intelecto. Com isso chegamos a uma resposta ao problema da impossibilidade de animais irracionais poderem conhecer os objetos segundo Kant. Já em Schopenhauer, diferentemente de Kant, os juízos, ou seja, as representações abstratas não são um produto do entendimento, mas

Sobre um entendimento irracional - Márcio Francisco Rodrigues Filho 
sim da razão, sendo o entendimento essencialmente intuitivo e não discursivo.

\section{Schopenhauer: um crítico da razão}

Schopenhauer faz esta leitura crítica de Kant e acaba reformulando a própria filosofia transcendental kantiana. Refuta as críticas do póskantismo, Schopenhauer apontará que o mérito de Kant foi justamente o de mostrar que o princípio de razão não consegue captar a coisa em si. Como o princípio de razão é agora a forma do objeto, Schopenhauer se instalará no sujeito; mas não através de uma relação de princípio e consequência e sim de simultaneidade. "Para Schopenhauer, Kant leva o pensar para dentro da intuição, quando admite que é um 'objeto irrepresentável' (o objeto em geral), aquilo com que faz com que a intuição se torne experiência" (CACCIOLA, 1994. p. 36).

A crítica as categorias se embasa no fato de Kant ter defendido que suas doze funções são predicados do objeto em geral (um objeto que é pensamento, mas não é intuído). Schopenhauer não aceita que Kant tome o entendimento como faculdade de julgar, mas não como faculdade intuitiva. Em Kant, os objetos são determinados por meio das categorias, extraídas da tábua lógica dos juízos. Essas categorias dominam todo o âmbito da possibilidade da experiência e do mundo objetivo. "Schopenhauer", por sua vez, "se contrapõe à sabedoria de uma faculdade de pensar, incapaz de conferir realidade as intuições, que não pode ser, portanto o autor da experiência" (CACCIOLA, 1994. p. 36). Assim, para Schopenhauer, Kant errou em não ter feito do entendimento uma faculdade de intuição. As consequências para a teoria da experiência de Kant são drásticas. Uma delas foi a postulação do objeto da representação, o objeto das categorias, como um objeto irrepresentável, uma mistura entre intuição e conceitos, um "andrógino", metade representação, metade coisa-em-si.

Schopenhauer acusa, assim, Kant de ter tratado o espaço e o tempo, bem como todo o mundo que Schopenhauer acredita ser da intuição (espaço, tempo e causalidade), de maneira superficial. Kant, portanto, teria negligenciado o fato de que o conteúdo empírico da intuição nos é dado. Outro erro foi o de ter submetido todas as coisas do mundo e tudo que acontece ao homem em favor de sua tábua de categorias. Mas isso, como sabemos, tem uma razão: fazer do objeto das categorias o próprio objeto da experiência possível, pois é somente pela intuição que o material da experiência é dado e, pelas categorias, pensado (KANT, 2001, p. A68, B93 ${ }^{2}$ ).

\footnotetext{
${ }^{2}$ Edições da crítica da razão pura: Edição A correspondendo a primeira edição e a edição B correspondendo à segunda.

Sobre um entendimento irracional - Márcio Francisco Rodrigues Filho
} 
Isso levou Kant a postular o entendimento mediado pelas categorias, sua faculdade de julgar, como a faculdade que nos possibilita conhecer o mundo empírico objetivo. É dessa dedução transcendental, contudo, que Schopenhauer busca escapar, a fim de livrar a filosofia transcendental kantiana do dogmatismo. Ora, para tanto, foi preciso tomar outro rumo: juízos relacionam-se apenas com conceitos e percepções com intuições. Isso explica porque o mundo objetivo em Schopenhauer é dado apenas pelo entendimento, uma faculdade intuitiva, e não abstrata-intuitiva. É o que nos torna semelhantes aos animais, pois animais também possuem essa mesma faculdade.

Segundo Schopenhauer, para que a doutrina das categorias de Kant se torne viável, ele terá de criar um "objeto da representação", que é o objeto das categorias, aquele que possibilita a experiência possível (já que Kant, após detalhar as formas universais da intuição, não detalha o seu conteúdo empírico, apenas coloca que isso "é nos dado de fora"). Kant, no entanto, é levado a um estranho dualismo, já que todo conhecimento passa a ter duas fontes completamente diferentes e não imediatamente relacionadas: a receptividade das ações, que é a capacidade de receber as representações, e a espontaneidade, que é como se conhece o objeto por meio dessas representações.

O conteúdo da razão como vimos nessa sessão, para Schopenhauer é um conhecimento intuitivo que nos é dado através de representações que nos são trazidas através de intuições empíricas pelo entendimento, uma função cerebral. Os objetos existem na intuição que é preenchida pelos sentidos ou pela imaginação. O que é, ao contrário, pensado é sempre um conceito universal, não intuitivo que pode ser um conceito de um objeto em geral: "mas o que pensar só se relaciona, mediatamente, por meio de conceitos, aos objetos, que, por si mesmos, são e permanecem sempre intuitivos (SCHOPENHAUER, 1991, p. 107).

Em Kant, devido à tábua das categorias, o objeto é aprendido no pensamento, levando o pensamento para dentro da intuição. Fazendo com que a intuição, por si só, seja sem entendimento (fato que impossibilita na teoria kantiana, os animais de conhecer os objetos), "puramente sensorial, totalmente passiva e que um objeto seja aprendido somente através de pensar (categoria do entendimento)" (SCHOPENHAUER, 1991, p. 105). Dessa forma, o objeto do pensamento se tornaria de novo um objeto, acabando por perder seu caráter de universalidade de abstração, pois ao invés de coisas universais receberia coisas particulares. O que faz Schopenhauer dizer que Kant levou o intuir para dentro do pensamento, pois ao "invés de conceitos universais, recebe coisas individuais como objeto" (SCHOPENHAUER, 1991, p.105).

Dessa "mistura" de conceitos e intuições é que teria se originado o "hibrido", o objeto da representação, isto é, o objeto da experiência possível, produto kantiano das categorias do entendimento. Contudo, o empírico, para

Sobre um entendimento irracional - Márcio Francisco Rodrigues Filho 
Schopenhauer, a experiência, já está na intuição. Ocorre que essa só se realiza através do entendimento, que aplica o nexo causal, "única função do entendimento, à sensação dos sentidos. A intuição é, portanto, efetivamente intelectual, o que justamente Kant nega" (SCHOPENHAUER, 1991, p. 108).

Ora, com isso fica claro o papel obsoleto da "coisa em si" kantiana. Como poderia, afinal, o objeto das categorias kantianas ser a própria coisa em si? Para Schopenhauer, como vimos na acusação de Jacobi, o objeto em si kantiano é algo que não precisa de sujeito; é individual, não está no tempo nem no espaço, mas também não é intuitivo, é somente objeto do pensamento, não sendo ainda, porém, pensamento abstrato. Enfim, a coisa em si kantiana é uma entidade fora de toda a cognoscibilidade (SCHOPENHAUER, 1991, p. 108). O erro de Kant estaria em justamente misturar pensamento e intuição, pois, para Schopenhauer, esse objeto transcendental é totalmente diverso da intuição, pois é com ele que a intuição se objetiva; contudo, ele nem é ainda conceito, porque essa é uma função das categorias enquanto conceitos a priori (acrescentar tal objeto a intuição): "A intromissão injustificada daquele andrógino, objeto da representação é a fonte dos erros de Kant (SCHOPENHAUER, 1991, p. 109).

A distinção feita por Kant entre representação e objeto da representação não faz, portanto, sentido para Schopenhauer. Porque, para que isso fosse sensato, seria necessário elevar o objeto da representação ao estado de coisa em si. Mas, se eliminarmos o objeto da representação, "a fonte dos erros de Kant", além de anular a crítica de Jacobi, estaremos eliminando também a doutrina das categorias a priori, pois essas não contribuiriam para que houvesse intuição e tampouco poderiam acessar a coisa em si. Admitindo a leitura de Schopenhauer de Kant como correta, conclui-se que só pensamos por meio das categorias os objetos da representações, transformando-os em experiência, pois toda a intuição empírica é experiência, o qual se chama empírica toda a intuição que se faz da sensação.

Schopenhauer, procurando evitar os problemas acima, pensa o entendimento como tendo uma única função: conhecer a priori a lei da causalidade. Kant não introduziu a lei da causalidade nas formas a priori pelo seu temor ao idealismo Berkeleyano; no entanto, com isso acabou por disfarçar o nexo causal sob o nome de "fundamento do fenômeno" (SCHOPENHAUER, 1991, p. 111).

Além disso, Schopenhauer nota, ao analisar os Princípios metafísicos da ciência da natureza de Kant, que as categorias kantianas "em nada seriam diferentes das ações formais de o entendimento no julgar", salvo que essas ações poderiam trocar o sujeito e o predicado de lugar. Kant define um juízo como "uma ação somente através da qual representações dadas tornam-se conhecimentos de um objeto". De acordo com Kant, diz

Sobre um entendimento irracional - Márcio Francisco Rodrigues Filho 
Schopenhauer, "há apenas conceitos de objetos, não intuições" (SCHOPENHAUER, 1991, p. 112). Ora, de acordo com isso, "os animais, já que não julgam, não poderiam conhecer nenhum objeto" (SCHOPENHAUER, 1991, p.112).

Schopenhauer está certo, portanto, em propor que atiremos as onze das doze categorias kantianas pela janela, ficando apenas com a da causalidade (SCHOPENHAUER, 1992, p. 112). Para Schopenhauer, o objeto existe primeiramente para a intuição e conceitos são abstrações dessas intuições, pois o pensamento abstrato precisa orientar-se exatamente de acordo com o mundo presente na intuição, limitando a função razão a abstrair as representações intuitivas.

Dessa forma, há três razões para concordar com Schopenhauer.Primeiro, porque se a teoria da experiência de Kant fosse correta, então animais irracionais, justamente por serem irracionais, jamais poderiam identificar e conhecer algo acerca dos objetos do mundo empírico. $\mathrm{O}$ fato é que os animais obviamente dominam e conhecem muito sobre os objetos que fazem parte do ambiente onde vivem. O talento do Cebus apella, mais conhecido como macaco-prego, em quebrar coquinhos certamente envolve conhecimentos adquiridos e algo sofisticado para um animal não dotado de razão. Esses "animais carregam por vários metros pedras com cerca de 1 quilo que usarão como 'martelo' até sítios de quebra - rochas planas ou troncos usados como apoio, chamados de 'bigornas', numa referência à base sobre a qual se malham metais" (MARQUES, 2007). Recentes estudos mostram que o macaco-prego embora tenha divergido a 40 milhões de anos de espécies como o gorila e os chimpanzés (animais mais próximos do homem na cadeia evolutiva) ainda assim, "o macaco-prego é candidato a se tornar um grande modelo para entender como a espécie humana evoluiu, por volta de 2,5 milhões de anos atrás, a ponto de conseguir usar machadinhas, martelos, arpões e outros instrumentos" (MARQUES, 2007) ${ }^{3}$.

Como explicar o talento desenvolvido por tais símios sem admitir que sua conduta pressuponha o uso de uma faculdade cognitiva elaborada, isto é, entendimento? Ora, se animais como macacos-prego não fossem dotados de entendimento, como explicar seu comportamento obviamente racional? Seguindo a teoria de Kant, teríamos ou de procurar alguma outra explicação natural para o fenômeno, ou teríamos que admitir que tais animais também unem conceitos a intuições por meio de categorias puras, o que seria implausível. Animais, afinal, não são seres reflexivos. Animais, com efeito, por serem desprovidos de reflexão, isto é, por não serem capazes

\footnotetext{
${ }^{3}$ Para saber mais sobre as proezas cognitivas e sociais do macaco-prego leia a reportagem publicada em agosto de 2004, intitulada: Gênio da Selva ("Gênio da Selva". In: Cientific American $\quad$ Brasil. $2004 . \quad$ Disponível em: <http://www2.uol.com.br/sciam/reportagens/genio_da_selva_imprimir.html.>. Acesso em 14 nov. 2011).

Sobre um entendimento irracional - Márcio Francisco Rodrigues Filho
} 
de abstrair, somente conhecem por meio de intuições. Ora, isso torna a exigência de Schopenhauer no mínimo plausível, já que o que confere realidade empírica a tais intuições, na teoria da experiência de Schopenhauer, é a intuição empírica, que é dada no entendimento, através das formas a priori do tempo, espaço e causalidade.

Em segundo lugar, penso que Schopenhauer é mais claro que Kant, pois sua distinção entre razão e entendimento é clara. Kant, por outro lado, como vimos, por vezes parece confundir entendimento e razão, tratando de forma simétrica e lógica seu sistema para que esse se encaixe e ganhe sentido, a ponto de tratar de ter de tratar de forma superficial o objeto que ele propõe a estudar profundamente, a saber, a razão. Kant faz da tábua das categorias o sustentáculo lógico de seu sistema, o que lhe traz problemas. Seus esquemas simétricos atrapalham ao invés de ajudar, pois, como vimos, Kant tenta por meio deles, sem alcançar soluções, mediar o intuir empírico e o pensamento empírico efetivado através de conceitos abstratos. Schopenhauer, contudo, ganha força nesse contexto, já que não apenas define de forma clara e direta o que entende por entendimento e razão, mas também nos fala sobre o material das intuições, o dado de Kant. Com isso, Schopenhauer não apenas explica como a experiência é possível, mas também como ela se efetua.

Em terceiro lugar, para Kant manter a sua dedução transcendental viável é necessário manter uma interpretação heterogênea sobre o juízo (dá unidade a diferentes produtos cognitivos: intuições e conceitos). Um kantiano, portanto, acaba sendo conduzido, assim, à conclusão errônea de que animais irracionais são incapazes de conhecer o mundo objetivo, uma conclusão absurda, já que animais obviamente entendem o mundo que os cerca. Claro, seu entendimento não se dá mediante conceitos, muito menos por dedução transcendental. $\mathrm{O}$ erro de Kant aqui denuncia que a causa de nossas representações precisa ser um objeto exterior a nós, fazendo dessa "coisa" que afeta as nossas representações a própria coisa em si, pois ela terá de ser o real, o empírico que é dado a nós em nossas intuições através da forma da nossa sensibilidade: tempo e espaço. Isso deixaria clara a postura dogmática da obra de Kant, pois a fonte de nossas experiências, que são os fenômenos seriam algo que ainda assim, seria desconhecido para nós.

Desta maneira, podemos dizer que os demais animais viveram antes que o homem, os vegetais antes dos animais, ou seja, o reino orgânico veio após o inorgânico e ainda, que o entendimento veio antes da reflexão isto é, do conceito, da abstração. Isso porque, para Schopenhauer, intelecto e matéria são correlatos, uma vez que "eles são apenas uma só e a mesma coisa, considerada de dois pontos de vista opostos" (SCHOPENHAUER, 2009, p. 129). Do ponto de vista do sujeito o intelecto é material, pois é um produto do cérebro e do ponto de vista do objeto a matéria é concreta, análoga ao próprio corpo que carrega o sujeito e ambos quando tomados juntos, formam o mundo como representação. E está ai o ponto: ao se abrir

Sobre um entendimento irracional - Márcio Francisco Rodrigues Filho 
"os primeiros olhos"; como dirá Schopenhauer, é que o universo teve sua realidade, pois estes são os intermediários indispensáveis do conhecimento. Sem os quais o mundo é inconcebível, uma vez que para o autor, o mundo enquanto fenômeno, que se apresenta no tempo e no espaço através das formas puras da intuição é mera representação de um sujeito dotado de intelecto, isto é, de conhecimento (SCHOPENHAUER, 1980, p.46).

Assim, dizer que os animais têm inteligência, de acordo com Schopenhauer, é uma verdade que pode ser deduzida, da intelectualidade da percepção, isto é, da aprioridade da lei da causalidade. "Todos os animais, até o mais vil, tem inteligência, isto é, conhecimento da lei da causalidade, mesmo que em um grau diferente de finura e clareza" (SCHOPENHAUER, 1950, p. 64), mas esse conhecimento da lei da causalidade é sempre o necessário para que os animais possam ter percepção de seus sentidos, "pois sensação, sem inteligência, seria, não só uma coisa inútil, mas uma crueldade da natureza" (SCHOPENHAUER, 1950, p. 64). Assim, para Schopenhauer é inegável que o conhecimento da lei da causalidade é $a$ priori nos animais, assim como nos homens e não um produto do hábito. Um cachorro ou um gato evita o fogo ou um precipício, porque ele é capaz de antecipar o resultado. Fazem a ligação de causa e efeito porque são dotados de entendimento, tem inteligência, portanto, são capazes de conhecer. Da mesma forma que se afastam de estranhos e tratam seu dono de forma carinhosa, pois tem a capacidade de perceber suas sensações de olfato, audição ou visão de maneira inteligente através do entendimento (tempo e espaço, ligados pela lei da causalidade).

\section{Referências bibliográficas}

CACCIOLA, Maria Lúcia Mello e Oliveira. Gottlieb. Schopenhauer e a questão do dogmatismo. São Paulo: Editora universidade de São Paulo, 1994.

. Schopenhauer e a crítica da razão - a razão e as representações abstratas. Discurso, n.19, jul./dez, São Paulo, 1989, p.91-106.

LEFRANC, Jean. Compreender Schopenhauer. Petrópolis, RJ: Editora Vozes, 2008.

MARQUES, Fabrício. Com pedras e varetas: macaco-prego usa ferramentas para quebrar frutos ou caçar formigas. Pesquisa Fapesp, São Paulo, n.135, maio 2007. Disponível em: < http://revistapesquisa.fapesp.br/?art=3226\&bd=1\&pg=1\&lg=>. Acesso em: 14 nov.2011.

MOREIRA, Jacqueline de Oliveira. O problema do conhecimento em Schopenhauer. Revista de Ciências Humanas, Florianópolis: EDUFSC, n. 36, p. 263-287, out de 2004.

PERNIN, Marie-José. Schopenhauer: decifrando o enigma do mundo. Rio de Janeiro: Jorge Zarar editora, 1995.

Sobre um entendimento irracional - Márcio Francisco Rodrigues Filho 
SCHOPENHAUER, Arthur. Crítica da Filosofia Kantiana. Tradução Maria Lúcia Cacciola. São Paulo: editora Abril Cultural, 1991. (Os pensadores, $5^{\mathrm{a}}$. Edição). Publicado com a obra $\mathrm{O}$ mundo como vontade e representação (III parte) e Parerga e paralipomena (capítulos V, VII, XII, XIV).

La quadruple raiz del principio de razón Suficiente. Buenos Aires: El Anteneo Editorial, 1950.

O mundo como vontade e representação. Porto: RÉS-Editora Editorial, 1980.

. Sobre a visão e as cores. São Paulo: Editora Nova Alexandria, 2003

Sobre la voluntad em la naturaleza. Madrid: Alianza Editorial, 2009 